\title{
Activation of methane using solid oxide membranes
}

\author{
J.E. ten Elshof *, B.A. van Hassel, H.J.M. Bouwmeester \\ University of Twente, Department of Chemical Technology, Laboratory of Inorganic Materials Science, \\ P.O. Box 217, 7500 AE Enschede, Netherlands
}

\begin{abstract}
Dense membranes of mixed-conducting perovskite-type oxides $\mathrm{La}_{0.6} \mathrm{Sr}_{0.4} \mathrm{Co}_{0.8} \mathrm{Fe}_{0.2} \mathrm{O}_{3}$ and $\mathrm{La}_{0.8} \mathrm{Ba}_{0.2} \mathrm{Co}_{0.8} \mathrm{Fe}_{0.2} \mathrm{O}_{3}$ were used for methane coupling by application of pressure-driven $\mathrm{O}_{2}$ permeation. High operating temperatures, typically above $800^{\circ} \mathrm{C}$, were needed to obtain reasonable oxygen fluxes. Conversions were small (1-3\%). Both compositions showed comparable $\mathrm{C}_{2}$ selectivities at low methane partial pressures. At higher pressures the selectivity to $\mathrm{C}_{2}$ hydrocarbons for $\mathrm{La}_{0.6} \mathrm{Sr}_{0.4} \mathrm{Co}_{0.8} \mathrm{Fe}_{0.2} \mathrm{O}_{3}$ increased to 67\%, whereas $\mathrm{La}_{0.8} \mathrm{Ba}_{0.2} \mathrm{Cu}_{0.8} \mathrm{Fe}_{0.2} \mathrm{O}_{3}$ showed small $\mathrm{C}_{2}$ selectivities. Strong surface segregation of $\mathrm{Sr}$ and $\mathrm{Ba}$ was shown by SEM for both compositions.
\end{abstract}

\section{Introduction}

Oxidative methane coupling has been investigated extensively, but due to the low yields obtained, no commercial applications have been realised to date. There is still considerable debate about the precise mechanism, although the active species is generally thought to be a reactive surface oxygen species, creating methyl radicals.

A new approach in methane coupling was introduced by Otsuka et al. [1], who used feed streams of methane and oxygen, separated by an oxygen ion conducting membrane made of yttria stabilized zirconia (YSZ). Oxygen was electrochemically pumped into the $\mathrm{CH}_{4}$ stream. It was shown that electrochemically pumped oxygen resulted in more selective coupling than gaseous oxygen $[1,2]$ and it has therefore been suggested that the catalytically active species is different in the case of pumped oxygen. The need for electrochemical pumping can be overcome by using dense mixed-

\footnotetext{
* Corresponding author.
}

conducting oxides, i.e. membranes which show selective permeation of oxygen. If a mixed-conducting oxide membrane is placed in an oxygen partial pressure gradient, oxygen anions will migrate from the high to the low oxygen partial pressure side. Electroneutrality of the membrane is maintained by a simultaneous flux of electrons or electron holes.

Several oxides of the perovskite-type $\left(\mathrm{ABO}_{3}\right)$ have been shown to be catalytically active in the coupling of methane $[3,4]$. Substantial ionic conductivity can be introduced in these materials by partial substitution of the A-site cation by aliovalent ions, whereas electronic conductivity is due to transition metal ions occupying the B-site. High oxygen permeation fluxes have been reported for perovskite materials, such as $\mathrm{La}_{1-x} \mathrm{Sr}_{x} \mathrm{Co}_{1-y} \mathrm{Fe}_{y} \mathrm{O}_{3-\delta}$ [5]. The main purpose of this paper is to demonstrate the application of pressure-driven oxygen permeation through dense membranes in the methane coupling process. The obvious advantage is that both the air separation 
and catalytic process are achieved in one single step. Furthermore, the active oxygen species may be different in the case of oxygen supplied through a membrane, possibly leading to higher $\mathrm{C}_{2}$ selectivities.

\section{Experimental}

\section{Perovskite-type oxide membranes} $\mathrm{La}_{0.6} \mathrm{Sr}_{0.4} \mathrm{Co}_{0.8} \mathrm{Fe}_{0.2} \mathrm{O}_{3}$ and $\mathrm{La}_{0.8} \mathrm{Ba}_{0.2} \mathrm{Co}_{0.8} \mathrm{Fe}_{0.2} \mathrm{O}_{3}$ were prepared by the EDTA method [6] and the citrate method, respectively. After calcining the powder at $925^{\circ} \mathrm{C}$ and sintering of the pressed pellets at $1225^{\circ} \mathrm{C}$ for $24 \mathrm{~h}$, the membranes were cut into disks ( $15.2 \mathrm{~mm}$ diameter; $0.5-2.0 \mathrm{~mm}$ thickness) and polished. Samples were characterized by XRD, EDX and SEM. Glass rings were used to seal the membrane to the quartz sample holder, thus creating two isolated compartments. Measurements were performed in the range of 800 $1000^{\circ} \mathrm{C}$. The experimental setup is schematically shown in Fig. 1. Gas leaks can be detected by GC detection of $\mathrm{N}_{2}$ in the lower oxygen partial pressure compartment. The contribution of molecular oxygen to the oxygen flux, due to leakages, was estimated to be below $3 \%$ in all cases, and typically well below $1 \%$. The GC contains a molecular sieve $13 \mathrm{X}$ for separation of $\mathrm{H}_{2}, \mathrm{O}_{2}, \mathrm{~N}_{2}, \mathrm{CH}_{4}$ and $\mathrm{CO}$ and a Porapak $\mathrm{N}$ column for separation of $\mathrm{CO}_{2}$, hydrocarbons and water. During all measurements reported here the carbon balance was in the range $99 \pm 2 \%$.

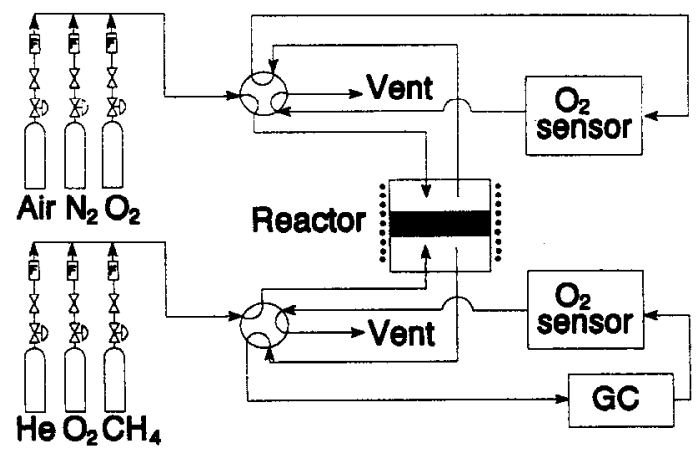

Fig. 1. Schematic diagram of experimental setup.

\section{Theory}

Using Kröger-Vink notation [7], the solid solution $\mathrm{La}_{1-x} \mathrm{Sr}_{x} \mathrm{MO}_{3}$ can be written in terms of the incorporation of $\mathrm{SrMO}_{3}(\mathrm{M}=\mathrm{Co}, \mathrm{Fe})$ into $\mathrm{LaMO}_{3}$ by

$$
\mathrm{SrMO}_{3} \underset{\mathrm{LaMO}_{3}}{\rightarrow} \mathrm{Sr}_{\mathrm{La}}^{\prime}+\mathrm{M}_{\mathrm{M}}{ }^{++3} \mathrm{O}_{\mathrm{O}}^{\mathrm{x}}
$$

The defect reaction describing the creation of oxygen vacancies is given by

$$
2 \mathrm{M}_{\mathrm{M}}+\mathrm{O}_{\mathrm{O}}^{\mathrm{x}} \rightleftarrows 2 \mathrm{M}_{\mathrm{M}}^{\mathrm{x}}+\mathrm{V}_{\mathrm{O}}^{\ddot{*}}+1 / 2 \mathrm{O}_{2}(\mathrm{~g})
$$

Furthermore, B-site transition metal cations can show charge disproportionation.

$2 \mathrm{M}_{\mathrm{M}}^{\mathrm{x}} \rightleftarrows \mathrm{M}_{\mathrm{M}}^{-}+\mathrm{M}_{\mathrm{M}}^{\prime}$

Thus by incorporation of $\mathrm{Sr}^{2+}$ in the $\mathrm{La}^{3+}$ sublattice oxygen vacancies are created, giving rise to ionic conduction. Electronic conduction is predominant in these types of materials. At the gassolid interfaces oxygen is incorporated at the highpressure side and released from the lattice at the low-pressure side of the membrane. The oxygen flux can be limited either by diffusion of oxygen through the membrane [8], or by a surface exchange process, e.g. the recombination of lattice oxygen to $\mathrm{O}_{2}(\mathrm{~g})$ or a reaction occurring at the interface, as was shown to occur in the case of high-temperature $\mathrm{CO}$ oxidation on $\mathrm{La}_{1-x} \mathrm{Sr}_{x} \mathrm{FeO}_{3}$ membranes [9]. In methane coupling the intermediate steps, in which water is produced and released from the surface, may be rate limiting in case of a very reactive surface.

\section{Results and discussion}

The XRD results for $\mathrm{La}_{0.6} \mathrm{Sr}_{0.4} \mathrm{Co}_{0.8} \mathrm{Fe}_{0.2} \mathrm{O}_{3}$ showed that its structure is a distorted cubic perovskite-type oxide. For $\mathrm{La}_{0.8} \mathrm{Ba}_{0.2} \mathrm{Co}_{0.8} \mathrm{Fe}_{0.2} \mathrm{O}_{3}$ a cubic perovskite was found.

In all catalytic experiments air was supplied at the high oxygen partial pressure side unless stated otherwise. The temperature-dependence of production rates and $\mathrm{C}_{2}$ selectivity for 
$\mathrm{La}_{0.6} \mathrm{Sr}_{0.4} \mathrm{Co}_{0.8} \mathrm{Fe}_{0.2} \mathrm{O}_{3}$ are shown in Fig. 2 . Between 800 and $900^{\circ} \mathrm{C}$ selectivities of $57-62 \%$ are reached at conversions of $1.1-2.3 \%$. The $\mathrm{C}_{2}$ selectivity decreases strongly between 900 and $950^{\circ} \mathrm{C}$, due to an increase of the $\mathrm{CO}_{2}$ production rate. In the same temperature range substantial production of $\mathrm{H}_{2}$ is observed. Since gaseous oxygen was present in the outlet stream, the selectivity drop can be explained by the subsequent deposition and oxidation of carbon from methane at high temperatures. The activation energy of oxygen permeation was calculated to be $169 \pm 6 \mathrm{~kJ} / \mathrm{mol}$. From these results $880^{\circ} \mathrm{C}$ was selected as standard temperature for further experiments, since both reasonable selectivities and oxygen fluxes are achieved here.

The apparent rates of production on a $1 \mathrm{~mm}$ thick $\mathrm{La}_{0.6} \mathrm{Sr}_{0.4} \mathrm{Co}_{0.8} \mathrm{Fe}_{0.2} \mathrm{O}_{3}$ membrane as a function of the methane partial pressure are shown in Fig. 3. The oxygen flux was $(8.38 \pm 0.49) \cdot 10^{-4}$ mol $\mathrm{m}^{-2} \mathrm{~s}^{-1}$ and no enhancement could be observed upon increasing the $\mathrm{CH}_{4}$ partial pressure. Fig. 4 shows that the relative amount of permeated oxygen consumed by oxidation $\left(X_{\mathrm{O}_{2}}\right)$ increases with $P\left(\mathrm{CH}_{4}\right)$, but even in a pure methane atmosphere only $74 \%$ of all permeated oxygen reacts. Selectivity increases to about $67 \%$. No deactivation of the catalyst was observed during a period of 2 weeks. Different samples with comparable thermal histories showed fluxes which differed by several factors of magnitude.

Experiments in which no oxygen permeation was allowed, and in which an amount of oxygen was cofed with methane, so that the total amount of oxygen was equal to that of permeated oxygen under similar conditions, showed somewhat higher conversions, but selectivities which were typically in the range of $25-35 \%$. Since molecular oxygen is still observed at the outlet in both types of experiments, the difference can not only be attributed to the absence of total oxidation by molecular oxygen in the gas phase. Thus, this may indicate the involvement of different oxygen species in these two modes of operation. These results will be discussed in more detail elsewhere [10]. However, due to the relatively high temperature

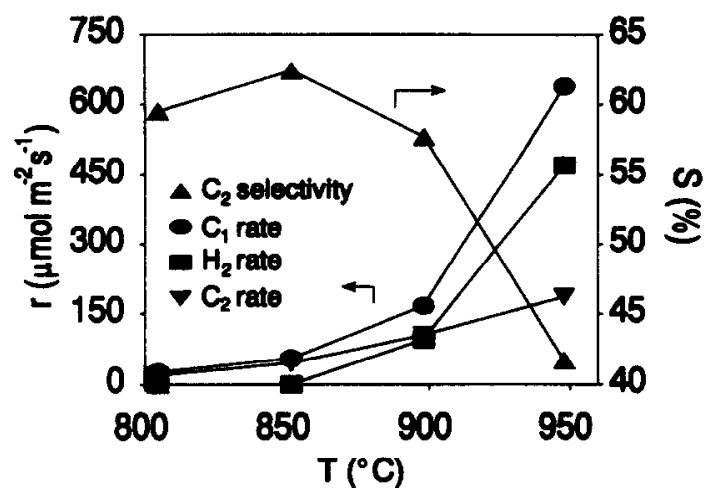

Fig. 2. Temperature dependence of catalytic activity and selectivity of $\mathrm{La}_{0.6} \mathrm{Sr}_{0.4} \mathrm{Co}_{0.8} \mathrm{Fe}_{0.2} \mathrm{O}_{3} . P\left(\mathrm{CH}_{4}\right)=0.25$ bar. $F=16.4 \mathrm{ml} / \mathrm{min}$.

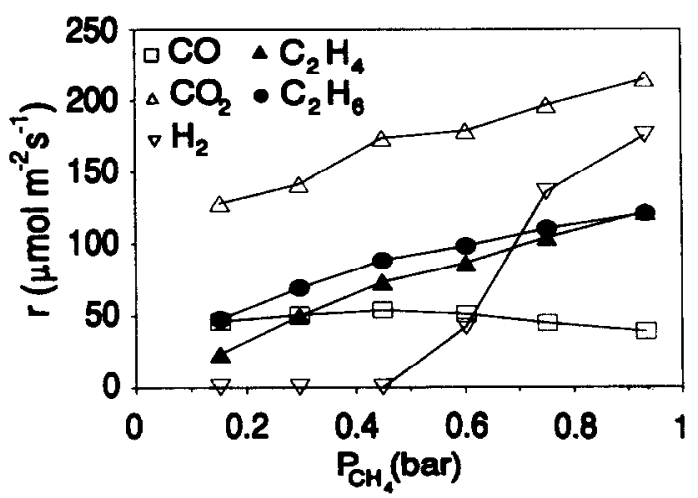

Fig. 3. Production rates at $880^{\circ} \mathrm{C}$ on $\mathrm{La}_{0.6} \mathrm{Sr}_{0.4} \mathrm{Co}_{0.8} \mathrm{Fe}_{0.2} \mathrm{O}_{3}$ as a function of $P\left(\mathrm{CH}_{4}\right), F=20.5 \mathrm{ml} / \mathrm{min}$

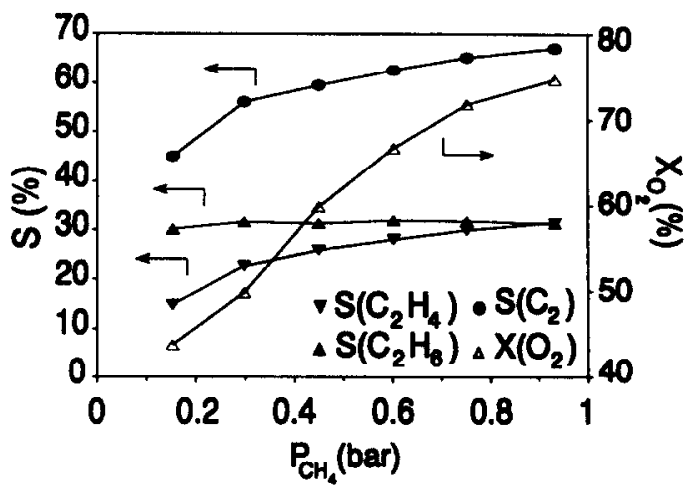

Fig. 4. Selectivity and relative oxygen consumption as a function of $P\left(\mathrm{CH}_{4}\right)$ on $\mathrm{La}_{0.6} \mathrm{Sr}_{0.4} \mathrm{Co}_{0.8} \mathrm{Fe}_{0.2} \mathrm{O}_{3}$.

at which these experiments were performed, the contribution of gas phase reactions will be significant.

The results obtained from permeation experiments on a $2 \mathrm{~mm}$ thick $\mathrm{La}_{0.8} \mathrm{Ba}_{0.2} \mathrm{Co}_{0.8} \mathrm{Fe}_{0.2} \mathrm{O}_{3}$ membrane, under the same conditions and having the same thermal history as the $\mathrm{La}_{0.6} \mathrm{Sr}_{0.4} \mathrm{Co}_{0.8} \mathrm{Fe}_{0.2} \mathrm{O}_{3}$ sample, differ strongly 


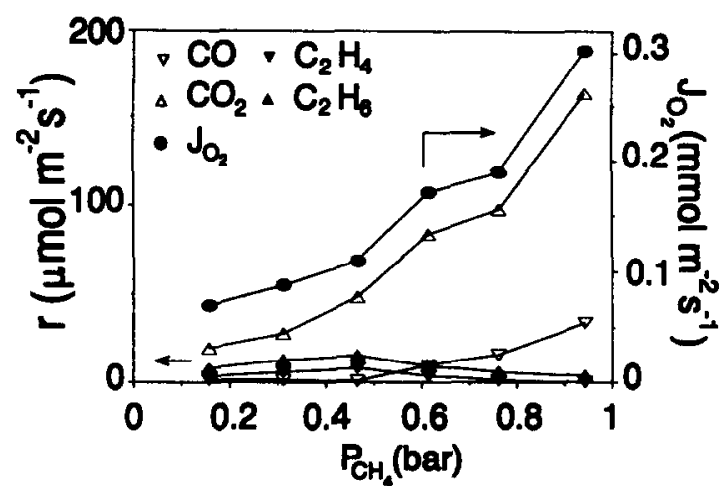

Fig. 5. The production rates and oxygen flux at $880^{\circ} \mathrm{C}$ on $\mathrm{La}_{0.8} \mathrm{Ba}_{0.2} \mathrm{Co}_{0.8} \mathrm{Fe}_{0.2} \mathrm{O}_{3}$ as a function of $P\left(\mathrm{CH}_{4}\right) . F=20.5 \mathrm{ml} / \mathrm{min}$.

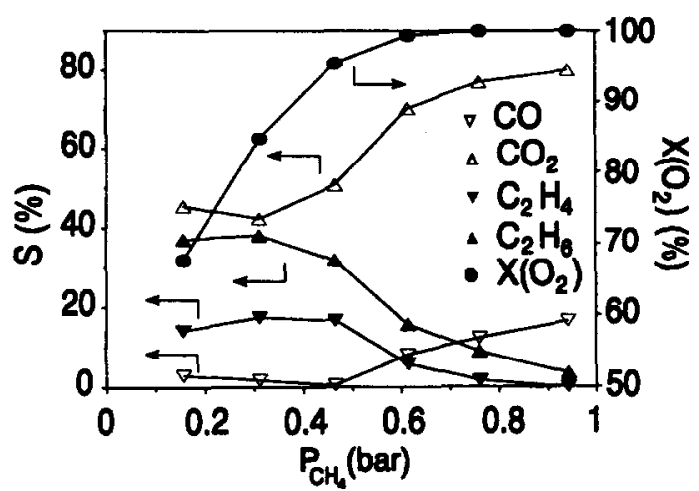

Fig. 6. Selectivity and relative oxygen consumption as a function of $P\left(\mathrm{CH}_{4}\right)$ on $\mathrm{La}_{0.8} \mathrm{Ba}_{0.2} \mathrm{Co}_{0.8} \mathrm{Fe}_{0.2} \mathrm{O}_{3}$.

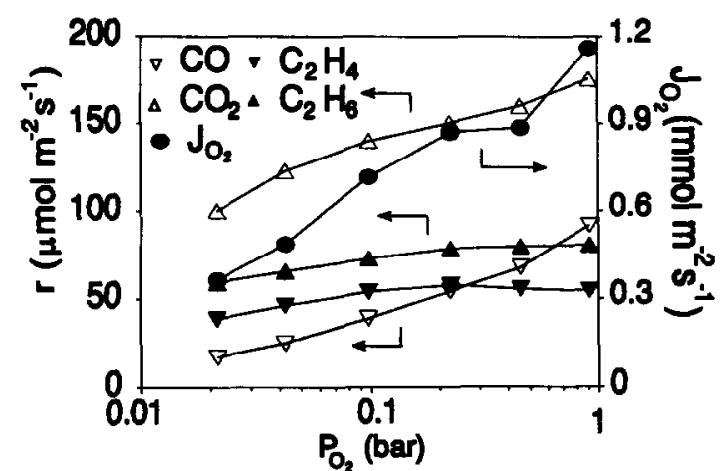

Fig. 7. The production rates and oxygen flux at $880^{\circ} \mathrm{C}$ on $\mathrm{La}_{0.6} \mathrm{Sr}_{0.4} \mathrm{Co}_{0.8} \mathrm{Fe}_{0.2} \mathrm{O}_{3}$ as a function of $P\left(\mathrm{O}_{2}\right) . P\left(\mathrm{CH}_{4}\right)=0.4$ bar. $F=20.5 \mathrm{ml} / \mathrm{min}$.

from the above (see Fig. 5 and Fig. 6). An increase of the oxygen flux was seen, which was virtually proportional to the square of the methane partial pressure. The $\mathrm{C}_{2}$ selectivity increases with $P\left(\mathrm{CH}_{4}\right)$ to a maximum of $56 \%$ in the range of $0.15-0.3$ bar $\mathrm{CH}_{4}$. At partial pressures above 0.5 bar the selectivity drops dramatically to finally reach $3 \%$. In the same pressure range $90-100 \%$ of all permeated oxygen is consumed. Furthermore, substantial hydrogen production is observed. A possible explanation is that carbon deposition occurred, followed by oxidation with all remaining unreacted $\mathrm{O}_{2}$. It appeared that the surface of the catalyst changes irreversibly under these conditions, since upon returning to methane partial pressures of about 0.25 bar the selectivity remained at very low values.

The dependence of the production rates and the oxygen flux on the oxygen partial pressure at the high oxygen partial pressure side of the $\mathrm{La}_{0.6} \mathrm{Sr}_{0.4} \mathrm{Co}_{0.8} \mathrm{Fe}_{0.2} \mathrm{O}_{3}$ membranc is shown in Fig. 7. The oxygen flux increases almost proportionally to $\log P\left(\mathrm{O}_{2}\right)$. The oxygen consumption varies between $52-75 \%$ and the increase of the oxygen flux mainly promotes the production rates of $\mathrm{CO}$ and $\mathrm{CO}_{2}$.

After the measurements the samples were studied by SEM and EDX. Pictures of the surfaces of two different $1 \mathrm{~mm} \mathrm{La} a_{0.6} \mathrm{Sr}_{0.4} \mathrm{Co}_{0.8} \mathrm{Fe}_{0.2} \mathrm{O}_{3}$ samples are shown in Fig. 8 and Fig. 9. The sample in Fig. 8 shows a strong segregation of $\mathrm{Sr}$ to the surface, whereas Fig. 9 shows a highly porous decomposed surface layer containing only $\mathrm{SrCO}_{3}$. $\mathrm{SEM}$ of the $\mathrm{La}_{0.8} \mathrm{Ba}_{0.2} \mathrm{Co}_{0.8} \mathrm{Fe}_{0.2} \mathrm{O}_{3}$ surface

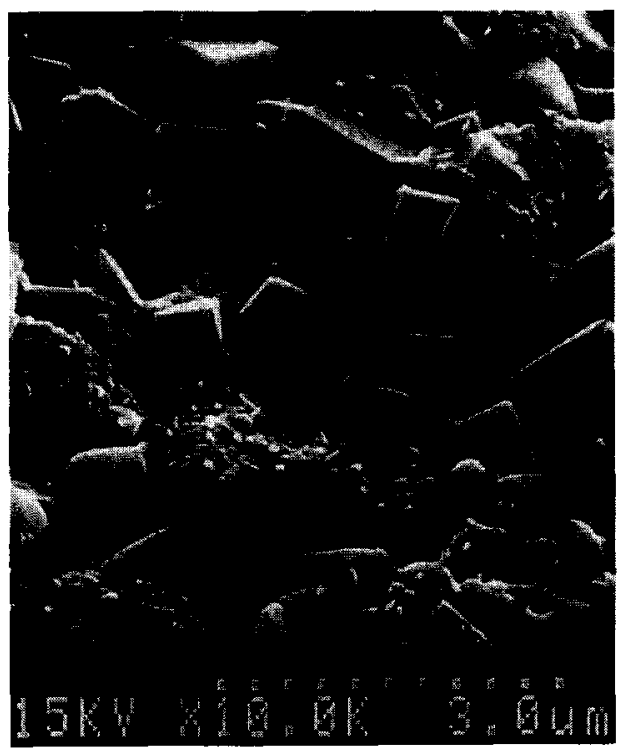

Fig. 8. SEM of $\mathrm{La}_{0.6} \mathrm{Sr}_{0.4} \mathrm{Co}_{0.8} \mathrm{Fe}_{0.2} \mathrm{O}_{3}$ surface showing $\mathrm{Sr}$ segregation. 


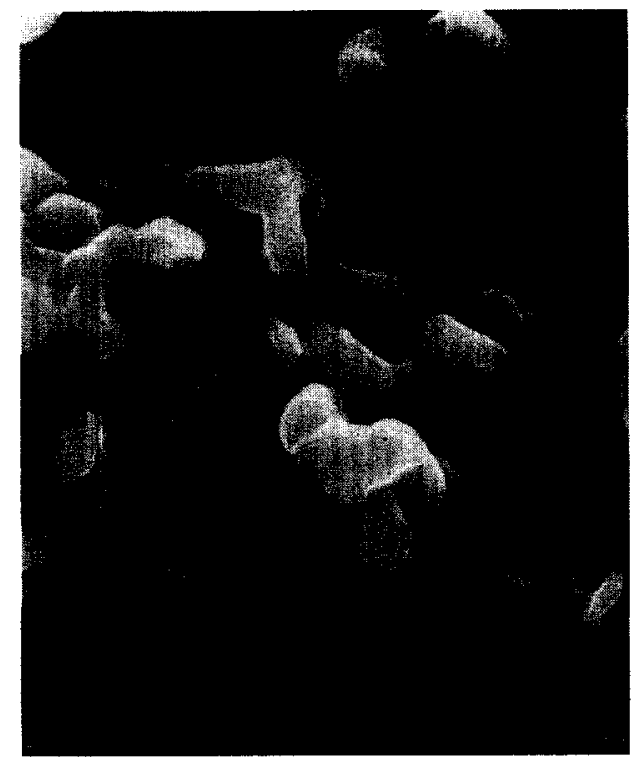

Fig. 9. $\mathrm{SEM}$ of $\mathrm{La}_{0.6} \mathrm{Sr}_{0.4} \mathrm{Co}_{0.8} \mathrm{Fe}_{0.2} \mathrm{O}_{3}$ surface showing decomposition.

showed segregation of $\mathrm{Ba}$, comparable to the $\mathrm{Sr}$ segregation shown in Fig. 8. Since the sample in Fig. 8 showed a much smaller flux than the one given in Fig. 9 this might be an indication of a surface controlled oxygen permeation flux. At present no clear explanation for the differences in segregation behaviour of different $\mathrm{La}_{0.6} \mathrm{Sr}_{0.4} \mathrm{Co}_{0.8} \mathrm{Fe}_{0.2} \mathrm{O}_{3}$ samples is available. However, it appeared to be strongly enhanced at conditions where carbon deposition took place.

No account can be given for the irreversible change of the catalytic behaviour of $\mathrm{La}_{0.8} \mathrm{Ba}_{0.2} \mathrm{Co}_{0.8} \mathrm{Fe}_{0.2} \mathrm{O}_{3}$. In the absence of gaseous $\mathrm{O}_{2}$ and in the presence of $\mathrm{H}_{2}$ such changes were also observed for $\mathrm{La}_{0.6} \mathrm{Sr}_{0.4} \mathrm{Co}_{0.8} \mathrm{Fe}_{0.2} \mathrm{O}_{3}$. Possibly a decomposition of the perovskite structure takes place at low oxygen partial pressures.

\section{Conclusions}

Dense perovskite oxide membranes $\mathrm{La}_{0.6} \mathrm{Sr}_{0.4} \mathrm{Co}_{0.8} \mathrm{Fe}_{0.2} \mathrm{O}_{3}$ and $\mathrm{La}_{0.8} \mathrm{Ba}_{0.2} \mathrm{Co}_{0.8} \mathrm{Fe}_{0.2} \mathrm{O}_{3}$ were applied as combined oxygen-supplying and methane coupling catalyst. The methane conversions were small. At low methane partial pressures the selectivities to $\mathrm{C}_{2}$ hydrocarbons were comparable for the investigated compositions. At high methane partial pressures the Sr-containing sample showed selectivities up to $67 \%$, whereas the selectivity on the Ba-containing membrane decreased to $3 \%$. Increasing the oxygen partial pressure in the oxygen-supplying chamber was shown to contribute mainly to the formation of total oxidation products.

Without permeated oxygen, in the presence of molecular oxygen cofed with methane, the $C_{2}$ selectivities appear to be significantly lower than in the permeation process. This may be an indication that different kinds of oxygen species are active in these two modes of operation.

Strong segregation of the earth-alkaline metal ions was shown by SEM for both compositions.

\section{Acknowledgements}

The support of the Commission of the European Communities in the framework of the Joule programme, sub-programme Energy from Fossil Sources, Hydrocarbons, is gratefully acknowledged.

\section{References}

[1] K. Otsuka, S. Yokoyama and A. Morikawa, Chem. Lett., (1985) 319-322.

[2] H. Nagamoto, K. Hayashi and H. Inoue, J. Catal., 126 (1990) 671-673.

[3] T. Hayakawa, H. Orita, M. Shimizu, K. Takehira, A.G. Andersen, K. Nomura and Y. Ujihira, Catal. Lett., 16 (1992) 359-371.

[4] K. Nomura, T. Hayakawa, K. Takehira and Y. Ujihira, Appl. Catal. A: General, 101 (1993) 6372.

[5] Y. Teraoka, T. Nobunaga, K. Okamoto, N. Miura and N. Yamazoe, Solid State Ionics, 48 ( 1991) 207-212.

[6] R.H.E. van Doorn, H. Kruidhof, L. Winnubst, H.J.M. Bouwmeester and A.J. Burggraaf, submitted to J. Am. Ceram. Soc.

[7] F.A. Kröger and H.J. Vink, in F. Seitz and P. Turnbull (Editors), Solid State Physics, Vol. 3, Academic Press, New York, 1956.

[8] P. Kofstad, Nonstoichiometry, Diffusion and Electrical Conductivity in Binary Metal Oxides, Wiley-Interscience, New York. 1972. 
[9] B.A. van Hassel, J.E. ten Elshof and H.J.M. Bouwmeester, Appl. Catal. A: General, 119 (1994) 279.
[10] J.E. ten Elshof, H.J.M. Bouwmeester and H. Verweij, to be published. 